\title{
But is it innovation?: The development of novel methodological approaches in qualitative research
}

\author{
Rose Wiles ${ }^{\mathrm{a}}$, Andrew Bengry-Howell ${ }^{\mathrm{b}}$, Graham Crow $^{\mathrm{c}}$ and Melanie Nind ${ }^{\mathrm{d}}$ \\ ${ }^{a}$ Co-Director and principal research fellow at the National Centre for Research Methods, University of Southampton \\ bResearch Fellow in the Centre for Sexual Health Research, University of Southampton \\ ${ }^{c}$ Director of the Scottish Graduate School of Social Science and Professor of Sociology and Methodology, University of \\ Edinburgh; Deputy Director of the National Centre for Research Methods, University of Southampton \\ ${ }^{d}$ Professor of Education and Co-Director of the National Centre for Research Methods, University of Southampton
}

\begin{abstract}
Focusing on three case studies of novel approaches about which claims of innovation have been made, this paper explores the process of methodological innovation and the response of the social science community to innovations. The study focuses on three specific innovations: 'netnography', 'child-led research' and 'creative methods' and draws on interview data with researchers who have developed these approaches and those who have engaged with them. Data are explored through the lens of the social context of contemporary qualitative research methods and specifically what has been referred to in the UK as the 'impact' agenda. We argue that while methodological innovation may be viewed by researchers as important for the continued success of social science disciplines, the processes whereby new methods are developed and marketed, within the context of contemporary social research and the impact culture, may limit their acknowledgement and acceptance within the broader social science community. This culture increases the speed at which innovations are developed and marketed, encourages the dissemination of codified or procedural approaches to innovations which limit the craft of qualitative research and encourages early career researchers to adopt approaches without being reflexive about the affordances these methods might provide.
\end{abstract}

Keywords: innovation, innovative methods, qualitative methods, impact agenda

\section{Introduction}

There are a number of pressures encouraging researchers to develop novel methodological approaches. The context of research is increasingly one in which the funding of individuals and institutions and indeed individual career progression rests on an ability to demonstrate novelty and research 'impact' (Travers 2009). One way of achieving this is through methodological innovation and it has been noted that research funders and publishers increasingly view methodological novelty as an important element in decisions about the funding of research and its subsequent publication (Taylor and Coffey 2009; Travers 2009). This environment encourages researchers to develop adaptations to established methods as well as to develop 'new' methods or at least to make claims for such developments (Wiles et al 2011). As well as these organisational and institutional pressures for methodological innovation, there are also drivers for methodological development to address new research questions arising from emerging social and economic challenges and changing patterns of social interaction. Qualitative researchers have been creative in experimenting with a range of

Correspondence: R Wiles, ESRC National Centre for Research Methods, School of Social Sciences, University of Southampton, Southampton, SO17 1BJ. Tel.: +44 (0)2380 594857 E-mail: R.A.Wiles@,soton.ac.uk

ISSN: 1748-0612online

DOI: $10.4256 /$ mio. 2013.002 
techniques, methods and methodologies for exploring and analysing social life and disseminating findings in response to these challenges (Coffey 2011).

There is limited research focusing on the process of methodological innovation. Xenitidou and Gilbert's (2012) study of international innovations occurring outside of the UK, and the subsequent special issue of this journal, explored some of the social processes involved in developing, promoting and disseminating methodological innovations. They note that methodological innovation comprises a set of processes driven by complex relations and papers in the special issue explored the role of practical issues, dissemination strategies and institutional support in driving and disseminating specific methodological innovations.

There is considerable debate about how innovation in social science should be defined (Xenitidou and Gilbert 2012). Some authors define it as applying only to new methods or methodologies while others extend the definition to apply to advances or developments of established methods (Taylor and Coffey 2008). The issue of uptake is also an important one. Some authors argue that a new approach or development is an innovation only if it has been taken up by the wider social science community (Taylor and Coffey 2008) while others define methodological innovation as approaches that have not yet filtered through to the mainstream (Xenitidou and Gilbert 2009, 2012). Many claims to methodological innovation appear to be largely adaptations of existing methods rather than new methodologies or designs (Wiles et al 2011). Regardless of the status of innovation claims, it has been argued that the drive to innovation has a detrimental effect on qualitative social science in that it encourages the development of poorly thought through and investigated 'fads' in social science methods which are, arguably, to the detriment of more established 'tried and tested' methods (Travers 2009; Housley and Smith, 2010; Wiles et al 2011). However, alongside this concern, it is recognised that methodological innovation is crucial for the future relevance of qualitative research and social science disciplines (Coffey 2011). In the current environment in which funding for social science research is under particular pressure qualitative researchers must be able to demonstrate that they are developing methodologies that have the capacity to provide answers to important social questions.

There are a number of tensions inherent in the drive to methodological innovation. Of primary interest to us here is the tension between the need to develop and experiment with methodological innovations that have the potential to address new and emerging research questions while at the same time demonstrating and persuading the broader social science community of the affordance and credibility of new methods in relation to other existing methods. A tension arises because of increasing pressure to develop and disseminate such innovations in relatively short time frames such that innovations are not necessarily subject to the critiques, discussion and debate necessary for their development into mature and robust methods which find credibility among the research community. This paper explores how these tensions are played out in the development of innovations using data from three case studies of approaches deemed to be innovative. In this paper we explore how three researchers describe the social processes of methodological innovation and uptake and responses to these innovations by key members of the social science community. We reflect on these issues through the lens of the social context of contemporary qualitative research methods and specifically what has been referred to in the UK as the 'impact' agenda, that is, the expectation that research will have a demonstrable academic, economic and/or societal impact. In this paper we seek to contribute to the discussions and debates raised by Xenitidou and Gilbert (2012) and other authors in the special issue of this journal on the process of innovation and also to further those debates through an exploration of the response of the social science community to innovation. 


\section{Methods}

Our project sought to explore the social processes surrounding methodological innovation. Specifically we wanted to explore how and why innovations are developed; the views of developers and champions about ownership, uptake and adaptations to innovations and the academic response (or impact) of innovations and patterns of uptake across disciplines. Identifying cases of innovation was far from straightforward. The criteria used to guide the selection of cases were that i) they had been in existence in some form for around 10 years, to allow time for uptake by the wider social science community; ii) they had been identified as 'innovations' through previous research (e.g., Bardsley and Wiles 2006; Wiles et al, 2009, 2011; Xenitidou and Gilbert 2009,2012 ) iii) they had a specific individual involved with their development and iv) they comprised a qualitative approach ${ }^{1}$. Additionally, the three cases were selected as exemplars of innovations which address methodological challenges such as enabling the study of a new area of social life, providing insight into aspects of social life that are not accessible by traditional methods or addressing the ethical, access or response issues raised by traditional methods or approaches. The cases identified were: 'netnography' developed by Robert Kozinets; 'creative research methods' developed by David Gauntlett and 'child-led research' developed by Mary Kellett. Each of these researchers have made claims, or had claims made on their behalf, about the innovative nature of their approach. Robert Kozinets describes himself as 'the creator of netnography' (http://kozinets.net/about) and netnography has been described as 'an innovation that crosses boundaries' (Xenitidou \& Gilbert 2009; see also Kozinets 2012). David Gauntlett describes himself as having 'pioneered the use of creative and visual research methods' (http://www.theory.org.uk/david/biog.htm) and he has been described as undertaking 'innovative visual enquiry' (Prosser, 2011). Mary Kellett describes her approach as 'a new paradigm' (Kellett 2005) and her approach is described as 'an inspirational and innovative programme' by one reviewer of her book on the publisher's website (http://www.uk.sagepub.com/books). We should note that these authors have not made 'grand' claims to completely new methodologies, rather the claims made are for an innovation or an innovative approach within their particular field. We are using these cases as examples of innovation, and of how social scientists respond to them. We now summarise these methodological approaches before going on to describe the methods we used in the study.

The case study of netnography sits within a broader methodological context of online or virtual ethnography which comprise approaches for conducting ethnographic studies of online communities and groups (see, for example, Hine 2000). Robert Kozinets developed his 'netnographic' approach to online research within the disciplinary field of marketing and consumer research, devising it initially as an online marketing research technique for studying online communities (Kozinets 2002). Netnography adapts traditional ethnographic research techniques to the study of cultures and communities that emerge though computer-mediated communication. Kozinets intends netnography to address many of the procedural, ethical and methodological issues that are specific to online research, and he has developed a step-by-step approach to its use (Kozinets 2010).This systematic approach, Kozinets argues, is what distinguishes the method from other forms of online ethnography, and justifies the use of a distinctive term to differentiate netnography from less-systematic approaches (Kozinets 2010).

David Gauntlett's innovation lies within the broad field of 'creative methods' which encompass a range of methods including visual, performative and sensory methods. This method is located within a broader range of approaches generally referred to as visual methods which comprise an array of different types of approaches and data (Prosser and Loxley, 2008). Gauntlett has been a leading proponent of a particular type of creative method in which study participants create something, such as a photograph, video, a drawing, a scrapbook or a model, which is then used within the research process in some way, usually for data elicitation purposes (Gauntlett 2007). His particular innovation has been around the creation of metaphorical models, particularly those created through the medium of Lego Serious Play. His method involves asking people to make their 
own model that represents some aspect of their personal or social identity; the research 'data' consists not simply of the created product, but also observation, discussion and analysis of the process of its production, in particular, the participant's interpretation of what they have produced and what it represents for them. This creative reflective method provides, Gauntlett argues, insights into how individuals present themselves, understand their own life story, and connect with the social world. Gauntlett has argued that this method provides an alternative to traditional interviews and focus groups in that it provides insights that do not emerge through more conventional methods and is accessible to participants who find verbal methods challenging.

Child-led research is an approach pioneered by Mary Kellett. The method involves providing training and support to children and young people to enable them to design and carry out a research project, led by them, from the initial idea through to its dissemination. Proponents of this method view enabling children to devise and undertake research on and about themselves as important from a moral and ethical standpoint, that is, because children are individuals in their own right and should be empowered to have a say in the decisions that are made about them and their lives. However, such an approach is also viewed as important from the standpoint of data quality. It is argued that children have privileged access to the culture of childhood which gives them a unique 'insider' perspective that is critical to adults' understanding of children's worlds. Adultled or managed research is viewed as less able to access or gain an understanding of children's worlds. This is a particular form of emancipatory research in relation to children and childhood (research by children, rather than 'on', 'for' or 'with' children). This method is located within a broader range of participatory approaches which include user-involvement, emancipatory and partnership research (Frankham 2009). Kellett published a book in 2005 based on her training programme which provides detailed guidance on training children in research methods and how to support children to conduct research of their own choosing (Kellett 2005). Kellett's approach involves training children in the use of a range of traditional methods; the innovation lies in the approach to research rather than in the research methods used.

Our research focused on these three cases of innovation. We have noted above that the creators of these innovations did not make 'grand' claims to innovation. While they have each set out the specific processes involved in 'their' approach and the ways in which they are novel, this has largely occurred in the format of text books outlining the approach. These have been subject to critiques from book reviewers but a systematic search of the literature indicated that the methods have not been subject to detailed debate and discussion in the academic or professional literature. It also indicated that the creators of these innovations have not explained in detail in any publications or other public fora how and why they came to develop their innovation. For these reasons we viewed it as appropriate to conduct in-depth interviews to explore these issues.

The study comprised in-depth interviews with each of the three 'innovators' as well as with five-six people per case who were able to comment on the usefulness, affordances and/or contribution of the method to social research. These interviewees included for each case: an early-career researcher who had applied the innovation; an experienced researcher working in the same field as the innovator; someone who had conducted a book review of one of the key texts relating to the innovation; someone from a different country to that of the innovator; and someone from a different discipline to the innovator. These individuals were identified from a range of sources: from a review of the literature; from our knowledge of leading academics in the fields in which the innovators worked; and from individuals identified by the innovator of people making use of 'their' approach (in the case of early career researchers). Four interviews were conducted via skype, one by email, ten by telephone and the remainder were face-to-face interviews in a venue of the interviewee's choosing. Interviews ranged from 30 to 120 minutes.

Interviews were fully transcribed and subject to thematic analysis. The process of analysis involved the research team reading and reviewing transcripts and identifying emergent themes. The innovator interviews 
were analysed separately to those commenting on the innovation. Emergent themes across both sets of transcripts were: timeliness; distinctiveness; contribution; uptake; and future developments. Within these categories, sub-themes were identified and general and specific points related to these were identified and highlighted. The analysis culminated in a summary for each case in relation to the key themes: 1) 'Why this, why now'? (what accounts for the development of the innovation, what accounts for its success, why it is timely, why this person and not others in the field) 2) Distinctiveness (what is innovative in the method/approach, similarities and differences to other approaches, and limitations of current methods/approaches); 3) Contribution of the innovation (to the substantive area, discipline or methods); 4) Breakthrough, acceptance and uptake (achieving academic legitimacy, differences according to area/discipline, who uses it and who doesn't, criticism, limiting factors); 4) Future developments (what is likely to happen with the method, whether it is here to stay, potential, what is needed for it to stay current, and others building on/developing the work).

A systematic search of the literature was also conducted to explore the academic response to these innovations (Bengry-Howell et al 2011) ${ }^{2}$. This comprised a systematic search of UK social science databases (Web of Science, OvidSP, CSA Illumina, Informaworld) for all citations in research or conference papers to the cases being investigated for the period 1/1/1999-31/12/2010. Google Scholar was also used to identify additional citations. Full references for each citation were entered into an Access database, and each entry was coded under the following categories: type of publication; academic discipline of the first author; geographical location of first author; type of citation (that is, whether the author applied, adapted, championed, cited or reviewed the methodological approach).

This study involved researching our peers and, as such, raised a number of ethical issues which have been reported in similar research (Wiles et al 2006; Wiles et al 2012). The nature of this research project, however, raised some additional challenging ethical issues relating to confidentiality, anonymity and risk. The core participants were invited to discuss their methodological developments in a study focusing on innovation and we, therefore, identified them as innovators. In some ways, we have defined these researchers as 'innovators' and we were conscious of our responsibility not to do so with the aim of subjecting them to public criticism in the dissemination of our findings. Anonymisation of these core participants was obviously impossible. By also inviting others to comment on their methodological developments, including those who may have been critical of them, we placed our core participants (the 'innovators') in a position where they were potentially vulnerable to public criticism and where they might have concerns about how we would make use of the findings and what the repercussions might be. While one of the outcomes of this might be that they were lauded as innovators, the possibility of them being criticised for over-claiming might also occur. We felt it was important to manage the dissemination of our findings carefully in ways that protected our core participants but at the same time enabled us to be faithful to our findings; this was at times a difficult balancing act. As well as making careful use of the data collected it has also involved us working closely with our case innovators, sending them a copy of their transcript for further comment and sending them a draft of all papers prior to submission for publication.

Ethical issues were also raised in relation to other interviewees who commented on the innovations; these related primarily to confidentiality and how our data would be reported. All these interviewees were anonymised and they were given a copy of their transcript for further comments. Some interviewees wanted parts of their transcript amended to clarify their comments or for some comments to be excluded from the analysis and/or reporting of the study. In these cases we went back to interviewees and asked them to express their views in ways in which they would be willing for us to use. This did not mean that interviewees were not critical of the innovations but rather that they did not want to be overtly critical of the individuals concerned. In this paper we have not included any identifiers in quotes from interviewees who commented on the 
innovations in the interests of preserving anonymity. While we have made every effort to anonymise these individuals, we recognise that it is possible that the core interviewees, and indeed others, may be able to make a good guess at the identity of at least some of them.

We now present the findings from our research focusing on the process of development of these innovations described by the individuals who developed them and the responses of the social science community to them.

\section{Why this, why now? The innovation journey}

Each of these innovators described different motivations for developing their innovation and different development journeys. However, each noted that they had not set out to develop an 'innovation'; indeed the initial development was identified as largely accidental. Each of the innovator respondents provided a different narrative to explain the origin of the innovation's development. For Kellett, her motivation was largely ethical; she noted 'What drove me was empowering children ... what I really wanted to do was to see if I could pioneer a way where children can be empowered to do their own research'. Kozinets' motivation was largely methodologically and technologically driven; in researching fan culture for his $\mathrm{PhD}$ in 1995, he found that much discussion was taking place online but that there were no clearly defined methods describing how research could be conducted with the vast amounts of data available or how to manage the ethical issues associated with the use of these data. Similarly Gauntlett described methodological reasons arising from his dissatisfaction with traditional methods as a motivation for developing different ways of conducting research with young people in ways that were more participatory. So, in the initial stages these methods were not viewed by their developers as innovation but rather a means of addressing shortcomings in existing approaches. So how did the potential of these initial developments gain currency and change from a method used by one individual to address specific problems in their research to one taken up more widely? Our data indicate that there are five interrelated factors central to this process: development, timeliness, support, accessibility and dissemination.

These innovators described a long process from the initial development of their innovation to it gaining recognition and legitimacy by the wider social science community. However, despite describing the development of the innovations as lengthy, there was a relatively short time period from the first dissemination of the method to uptake by the broader community. Kellett described an 'uphill struggle' over three years during which time she developed and piloted her approach before having a breakthrough. The 'breakthrough' occurred when the Children's Research Centre (CRC) was set up at the Open University in the UK in 2003, followed by early publications in the area in 2004 and publication of a key text book in 2005. This point marked the beginning of a fairly rapid increase in the number of citations as well as considerable media interest in the approach ${ }^{3}$. Gauntlett described a long process starting with his $\mathrm{PhD}$ in the mid-1990s. However, he reported returning to the area of creative methods in 2002, developing a website in 2003 and being contacted by Lego Serious Play in 2004. He received considerable publicity for his approach with Lego in $2005^{4}$ and published a book on his approach in 2007 which marked the beginning of a rapid increase in citations. Kozinets similarly charted the development of his method from his $\mathrm{PhD}$ over a period of time. Following his $\mathrm{PhD}$ in 1995, he published a paper reflecting on the method in 1998 and a key paper which he commenced in 1999 was finally published in 2002 which marked the point of a rapid increase in citations. He published a book outlining the method in 2010 .

Our citation search provides some indication of the trajectories of these innovations in terms of their recognition, acknowledgement and uptake across the social science community (Bengry-Howell et al 2011). Figure 1 illustrates the numbers of citations and their trajectories. As would be expected, the trajectories of citations coincided with the publication of key texts on the methods and these are marked on Figure 1. Netnography had 138 citations, $42 \%$ of which were cases where the method was applied. The majority of 
citations were from the disciplines in which the method originated, broadly management and business studies. Many of the citations were from authors from North America where Kozinets is based (40\%) but there were citations from authors in a wide range of other countries, particularly the UK as well as Australasia and Hong Kong. Gauntlett's creative methods had 37 citations and most of these $(76 \%)$ were references to the method rather than applications of it in which it was referenced along with other approaches within methodological narratives that served to position a particular study, or broadly consider the range of different methodological approaches within a particular field. Around one third of the citations were in media and communication studies, the area in which he is based, with the others distributed across the social sciences, particularly education. While just over half of citations are from UK-based researchers, there are also citations from authors based in other European countries, particularly Denmark, as well as Australia. Mary Kellett's childled research approach had 76 citations; these were also mostly citations in which the method was referenced $(80 \%)$. Citations came from a range of disciplines, mostly education, children's research and childhood studies but there were also citations in the disciplines of sociology, social work and other social sciences. The majority of citations were from UK-based authors, where the approach originated, but there were some citations from authors in Australia, the US and Canada.

\section{Figure 1: Citations of all 3 Cases by Year}

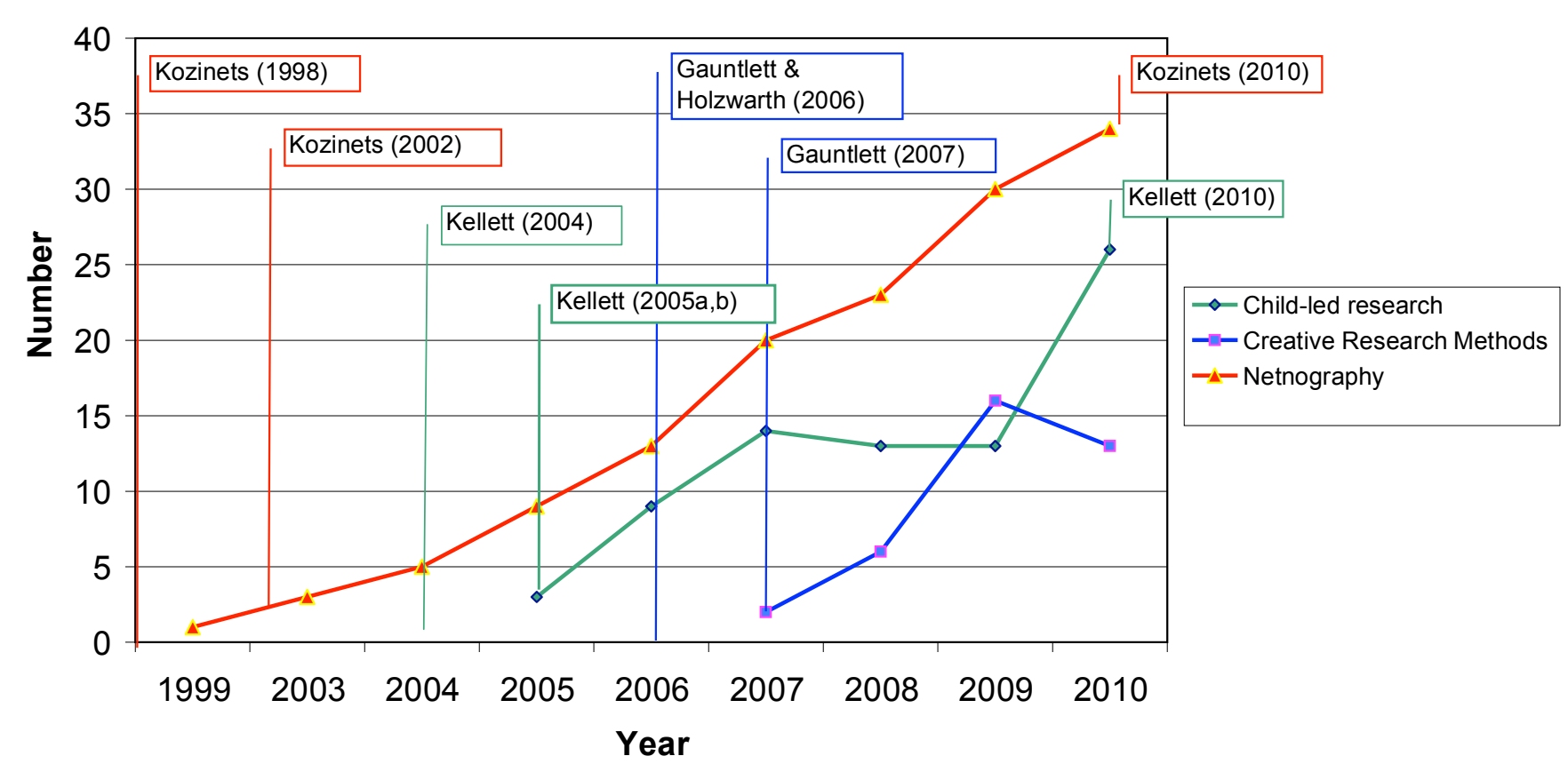

Data indicate that, for innovations to 'take off', they need to be the right method for the right time; the conditions needs to be right for them to be accepted and they need to resonate with topical issues or debates. This was the case for each of these innovations and is a central factor in their relatively rapid uptake. Kozinets' innovation was a response to the increasing use of the internet and social media in the forming of culture and community and in everyday interactions (Dutton and Blank 2011). This is an area in which there is a burgeoning interest as researchers seek to adapt methods and techniques for studying social interactions and social worlds online (Hooley et al 2012). Kellett's approach resonates with theoretical developments and topical debates about research participants' rights and the broader rights agenda. Specifically, it links into debates developments and policies in relation to children's rights and empowerment, such as the United Nations Convention on the Rights of the Child (http://www2.ohchr.org/english/law/crc.htm), The UK Government's 2004 Children's Act as well as a growing awareness of, and commitment to, research which 
recognises children's agency (see Kellett 2010). Gauntlett's approach resonates with an increasing interest in creative, visual and sensory methods and in arts-based approaches and an attempt to transcend the limitations of verbal methods (Pink 2009; Mason 2012; Prosser and Loxley 2008). It forms part of what has been referred to as the 'cultural turn' in social science (Friedland and Mohr 2004). It also resonates with developments and debates in participatory methods and the drive towards 'user involvement' in research that aims to give research participants choice and control over their interactions with researchers (Frankham 2009). In each case, these approaches can be seen to be timely in that they comprised a method or approach that addressed specific concerns or questions in qualitative research.

This timeliness is reflected in the support that colleagues and institutions provided to these individuals. The innovators were all fairly junior academics when they first developed their method or approach. The support of key people within their discipline and of their institutions was important in encouraging them to further develop it and to be confident about disseminating or publicising it. An acknowledgement that they were 'on to something' by key people in a discipline was a feature in the initial development of these innovations. Robert Kozinets for example reported that following an early presentation of his work at a conference 'big names in my field ... said the internet stuff is really interesting, you should definitely keep doing that'. Subsequent institutional support was also important in encouraging the development and dissemination of the method. One of the interviewees in Mary Kellett's case described supporting her work which enabled her to establish the Children's Research Centre at her institution. Active championing of the developing approach, as well as of the innovator, was also important in getting the method known and gaining legitimacy for it. Our data indicated that this could serve both the interests of the innovator and the people championing the work. One of the interviewees in Gauntlett's case, for example, noted:

'My thing was getting visual methods accepted and David's [approach] was part of that overall agenda, and he formed an important building block in doing that ... I believe in what he is doing and I know what he's up against so I'm trying to promote him and get him heard by more people'

Recognising and acknowledging that they were 'onto something' in the development of their method or approach encouraged these researchers to broader dissemination of it. Rogers' (2003) classic study of innovation identifies publicity, as well as the role of champions and opinion leaders, as central in the process whereby innovations achieve 'breakthrough' status. In the cases focused on here various strategies were adopted to disseminate and publicise the innovations in order to get them more widely known in the social science community. One of the key strategies was to develop and disseminate a clear set of procedures that could be followed by researchers with an interest in taking up the method. This also served the purpose of ensuring that the innovation was used in the specific way outlined by its originator. Each of the individuals in these cases published a book setting out procedures for their method or approach (Gauntlett 2007; Kellett 2005; Kozinets 2010) in which they employed what Bryman has referred to as 'rhetorics of persuasion' to convince readers of the validity of their approach (Bryman 1998:142). They also ran training events to teach people about the approach. For Kozinets, a further strategy was to give his method a specific name to delineate it from other similar methods and in order to indicate the specificity, distinctiveness and novelty of the method and that he had generated it, and had some ownership of it. The development of websites as well as the use of blogs and social media were also used, particularly by Kozinets and Gauntlett, to reach out to the wider community and to engage them with their method (http://www.artlab.org.uk/; http://kozinets.net/). Kozinets and Gauntlett were identified by other interviewees as proficient at self-promotion of their methods; Kozinets in particular has identified how successful practices from brand marketing can be used in the diffusion of methodological innovations (Kozinets 2012). 
Despite describing a long period of development of these methods each had a relatively rapid and significant impact in the social science literature, and in the wider media, following the publication of their work. They each appeared to generate popular enthusiasm and a keenness for uptake. Kellett, for example noted:

'It's taken off, I would say, big time now, because it's all the way round the World. I mean, my email box is just full from people all over the place wanting either advice or suggestions because they want to do something [or] they want to get something off the website or whatever. I mean, you know, Mexico, Indonesia, all over the place.'

Robert Kozinets similarly describes initial interest in netnography followed by widespread acceptance:

'It's now perceived, and I would say fairly accurately, as being fairly deep, fairly widespread in terms of a whole global network of qualitative consumer researchers who know this method and a number of them are using it and adopting it and adapting it ... I've got a number of colleagues who are using it well just all over the place, Turkey, Finland, France.'

Gauntlett was more reticent about acknowledging uptake but noted:

'It's become noticed. You know, it's the kind of thing that, when people are compiling their handbooks of qualitative methods, they probably nowadays tend to think, well we should probably have a chapter on that.'

There are a number of tensions in elements of this process. The momentum of these innovations, fuelled by their timeliness and subsequent popularity, means that they have taken off relatively fast. This poses a number of challenges which we now explore.

\section{But is it innovation?}

A central issue raised in the interviews with academics who commented on these innovations was of the importance of innovation and of individuals willing to push boundaries, take risks and experiment with new methods. Innovation was characterised as essential for the development of social science disciplines and their ability to answer new questions and investigate emerging areas of social life. It was recognised that most academics tend to stick with tried and tested methods with which they are comfortable and that innovating takes a special kind of person. People who develop methodological innovations were characterised as being creative, determined, committed, enthusiastic, courageous and able to 'think outside the box'. One interviewee, an experienced methodologist, commenting on one of the innovators said:

'I liked the approach because it was sort of thinking outside the box really and they were willing to try and experiment with things and were quite an enthusiast, I suppose, and that really came across ... I like to see people try new things really I suppose and they seemed to be doing that in quite an exciting way ... they came across as somebody who wanted to try new things and think differently and I applaud that, I really do.'

However while interviewees were positive about the importance of innovation and the importance of people willing to innovate they also raised some reservations about these cases of innovation and about methodological innovation more generally. These centred around four concerns: the uniqueness of innovations; the speed of development and dissemination; codification of innovations; and, the response of the social science community to innovation.

The development of completely new methodological innovations in social science is a rare event (Alasuutari 2007). Methodological development in qualitative social science is characterised by adaptations to tried and 
tested methods, the transfer of methods from other disciplines and changes in technology which enable researchers to collect or analyse data in different ways (Wiles et al 2011; Xenitidou and Gilbert 2009, 2012). All developments in social research methods inevitably build on methods developed by others, a process Wild describes as 'conceptual composting' (Wild 2012). Development is characterised as being what Rogers (2003) has referred to as horizontal rather than top down; that is, rather than innovations being adopted wholesale from a central key innovator, developments are diffused across a community and they are adapted and developed as the community learn about and engage with them. In this model, knowledge and practice is cumulative; in social science Kuhn's (1962) notion of paradigm shifts where one approach gives way to a completely different one does not tend to occur. It is also the case, as Johnson (2010) has noted, that innovations are often developed simultaneously, but independently, by different individuals at a specific point in time. This context makes claiming ownership of a new method problematic in that developers are inevitably 'standing on the shoulders' of past developments and in addition other people are likely to develop similar methods at the same time.

A frequent observation made by interviewees commenting on the innovation cases was that they were not necessarily new and not wholly distinct from other, similar methods. It was observed that while there was an element of innovation in each of the approaches, and indeed the merit or value of the approaches was acknowledged, there were nevertheless parallel developments in which these approaches were embedded and, in some cases, similar approaches that preceded them. This was not to deny the importance of the approaches focused on in this study; indeed, each was seen to add something specific to the broad methodological field in which they were located. Nevertheless, interviewees questioned the extent to which these could be defined as innovations in that they were embedded in broader developments by other researchers in the area or in other disciplines or cultures. The innovations were referred to by some interviewees as being 'slightly different', taking approaches 'a step further' or having 'some innovative elements':

'What I can't see from where I'm standing is a very distinctive perspective that makes netnography different from Hine's virtual ethnography or different from the kind of work that lots of people are doing ... but it's not everybody who is in this field [who] writes methodologically about what they are doing in as big a way as he [Kozinets] does which does take the stuff beyond just being a sort of 'how to' book actually.'

'I thought [it] was really innovative in terms of children. I think what I'm saying is that if you then look at the parallel literatures around other groups there was a lot of connections there, and that's about the epistemological basis of what Mary [Kellett] was doing. You know, the assumptions about how we involve lay researchers in research, why we're doing it, how it shapes knowledge, who gets to count as a credible researcher, all these things, these debates, were embedded in sociology.'

'It wasn't a completely new idea to me but I hadn't seen it done with Lego. I think he [Gauntlett] was doing something a bit different, not entirely different but a bit different and he was showing in his approach a willingness to think differently and I suppose all of that is quite innovative.'

Central to interviewees' comments was a questioning of the concept of innovation and a concern about the negative consequences of the drive for innovation. Interviewees noted that the drive for innovation, coupled with the 'impact' agenda, encouraged the development of methods that might be seen as 'gimmicks' rather than methods that are carefully considered, developed and evaluated over time. Central to these concerns was a view that the process whereby innovations reach a level of maturity occurs through them being subject to critiques from the wider social science community and through their use and adaptation by the innovator as well as other social scientists. This process was viewed as crucial for methods to gain broad acceptance by the social science community. This process runs counter to the drive for impact, which is highly individualised. 
One of our interviewees noted that the impact of methodological innovations is a slow process but that this is in conflict with the expectations of funding bodies who expect impact by the end of the lifetime of a project, not 15 or 20 years later. In the cases focused on here, as we have discussed, the timeliness of these innovations gave them a momentum that meant that they gained attention, at least initially, in relatively early stages of the development of the method.

A related tension inherent in the drives for innovation and impact is that it encourages the marketing of innovations and indeed innovators. There was a sense of distaste in interviewees' responses in relation to marketing and 'self-promotion', perhaps reflecting some academics' discomfort with the trend towards the marketization of academia, perhaps particularly in the UK (Kozinets 2012). As is common practice, these innovation cases have made use of e-resources and social media to publicise their work and to gain recognition of the method as well as themselves. Their approaches have also been marketed through publishers who encourage a particular style of publication. To achieve uptake, approaches need to be accessible and feasible; researchers need to understand the method and how to use it. This encourages a style of writing in which approaches are 'codified' and procedures are set out. One of our interviewees noted that there is a trend towards publishers encouraging this type of publication of methodological innovations:

'There is an issue about publishers developing a kind of house style for methods text books which takes you through [a method], it holds your hand and I don't want to say there is a dumbing down in that because I don't think there is but I do worry about it at some level, that maybe it's a bit hegemonic and, you know, students sort of expect to be kind of taken through things and not perhaps challenged as much as they could be ... it's a bit too packaged.'

The trend towards proceduralism in research and codification of methods has been observed by others (Hammersley 2008). It may be related to, or at least congruent with, the drives for innovation and impact. Some interviewees noted that there are broader negative impacts arising from this. Specifically they noted that it meant that the creative 'craft' of qualitative research was undermined in favour of procedural approaches to research which was regarded to be to the detriment of qualitative social science.

A related tension arising from the marketing of approaches is that new methods or approaches get 'rolled out' and become seen as 'the' method that researchers at the cutting edge of social science 'should' be using. Our interviewees noted that this encourages researchers to adopt approaches because they are new and seem exciting but without really thinking through why they are using them.

'I worry about innovation being, well I worry about the politics of it. I worry about it being this big machine, you know, which the whole aim is to just churn out something just because it's new and I don't think, just because it's new means it's going to be any good ... what I don't like, what I suppose I would worry about, is people sort of thinking, here's a new trendy, tricksy method, I'm just going to try it for fun, you know without thinking, now why would I do that, and what would it do and how would you understand the kind of data that might emerge from that?'

'Most innovations within the social sciences methodologically are worth looking at and are interesting. My concern is that they tend to then get rolled out and of course, you know, it depends on what you are trying to achieve. So I'm sure we went through years after the work of the CRC in which people felt that, if they were doing work with children at all, it should be child-led, and often that was regardless of what the research question was ... for some people it was maybe being caught up in a zeitgeist of thinking this is what we should be doing.'

Our analysis of data from the interviews with people commenting on these innovations indicated that while methodological innovation is viewed as important for the continued success of social science disciplines, at 
the same time the process whereby 'innovations' are developed and marketed, within the context of the impact culture, limits their maturity and consequently their acknowledgement and acceptance within the broader social science community. This culture is viewed as increasing the likelihood of over-claiming, of not acknowledging the antecedents to innovations and of the dissemination of codified or procedural approaches to innovations. This has been identified as limiting the craft of qualitative research and encouraging early career researchers to adopt approaches without being reflexive about the affordances these methods might provide.

\section{Discussion}

It is important to reiterate here that we have not intended to set up these cases of innovations in order to subject them to criticism or to question the extent to which they can be regarded as innovations. Rather our aim in this paper was to use these cases as illustrations of the more general trend towards researchers developing methodological innovations and to allow us to explore the social process of such developments and the responses of the social science community to them. It is also important to note that the researchers focused on in these cases did not make grand claims to innovation. They did not state that their specific methodological development should replace other existing methods or should be adopted wholesale. Nevertheless, developing methods is a risky business; we echo the views of many of our interviewees who commented on these innovations that it is important for the health of social science that people are willing to take risks in developing new methods and they should be applauded for doing so.

Exploring contemporary innovation is a difficult task. The big breakthroughs in any area are not always apparent at the time; it is only with the benefit of hindsight that it is possible to see what is a major and lasting development and what is, in Travers' (2009) language 'a fad' that will not stand the test of time. Lee's (2011) careful historical analysis of the rise and fall of the non-directive interview and, with Fielding (Fielding and Lee 1996), of the history of computer assisted qualitative data analysis (CAQDAS) demonstrate the importance of looking at developments over a long period and of applying a historical perspective to methods which have gained contemporary currency, not least because of a tendency to ignore or 'forget' the contributions of the past to these methods (Lee 2011: 142). Our focus here on three contemporary innovations which have gained some currency in the last few years means that we can make only a conditional judgement about what are plausible candidates for innovation. At present it is impossible to tell what impact these methods or approaches will have over the longer term.

It is interesting to observe researchers' responses to these innovations and to innovation more broadly. Despite a desire for innovation and a concern about the need for social science to keep developing and renewing itself there appears to be a tendency to conservatism and a distrust of innovation, perhaps especially among established academics. This may reflect real concerns with the rigour and robustness of the innovation cases and we discuss this issue below. However, it may also reflect a resistance to novelty or alternatively, be a feature of competitiveness between academics. There certainly appeared to be a distrust of marketing and self-promotion despite this being encouraged in academic institutions and increasingly being a feature of academic life. Critiques of these innovation cases do not necessarily mean that they are immature developments. It may be that they reflect what Hirschman (1991) referred to, albeit in a different context, as the rhetoric of reaction; that, in the face of suggested change to an established order, there is a tendency to conservatism and to employ narratives of futility ('it will fail'), perversity ('it will make things worse') and jeopardy ('it risks endangering previous accomplishments'). The latter may be particularly relevant here, especially in relation to Travers' (2009) view that new 'fads' risk established and rigorous methods falling out of use. Lee's (2011: 142) assertion that sociology tends to refer nostalgically to a 'golden age' associated with ethnography emerging from the Chicago School is perhaps pertinent in relation to this argument. It is also 
important to note that the history of innovation is replete with cases of innovators who have initially been ridiculed for developments which have later become mainstream (Johnson 2010)

Despite these caveats however, our research has identified the importance of situating contemporary methodological innovation in its social context, particularly, but not exclusively, in relation to the impact agenda. One important observation is that researchers appear to be aware of, and to be reflexive about, the potential for demonstrating innovation in their work in a way that most researchers in the past possibly were not. Some academics have argued that there are distinct phases in the history of qualitative research methods with each being characterised by a different approach to research and the use of different methods (see Alasuutari 2007; Savage 2010). The current social context of research methods has been described by these authors as one in which innovative methods to engage with the challenges of participatory and democratic research as well as with the informational age have come to the fore. Certainly there is considerable innovation occurring in relation to the harnessing of new social media in social research and much of this transcends the qualitative/quantitative divide. While these phases may be marked as much by continuity of some methods as by change in terms of new methods being developed, the social context of qualitative research in the current period can be characterised as having some specific features. The current context of methodological development is one in which there is greater cross-fertilisation across disciplines and indeed a general fragmentation of disciplines. This is accompanied by greater opportunities for the rapid dissemination of developments; through social media as well as more conventional publications. Expectations from funders, such as the UK Research Councils, of demonstrable research impact and opportunities for 'knowledge exchange' activities are also key features of contemporary academia. Alongside these developments is the increasingly blurred boundary between journalism and academic research and between 'citizen' journalists/ lay researchers and professionals. These, we argue, contribute to a context in which methodological developments and their dissemination are speeding up. Arguably, methodological innovation, at least as regards innovations that are likely to stand the test of time, is a slow process involving an initial idea, experimentation, further development, initial dissemination and opening it up to critique from others, further development in the light of critiques, further experimentation and so on. Such a process runs counter to the various pressures currently at work in academia. Whether this will contribute to the continued success of social science or be to its detriment remains to be seen.

\section{Notes}

${ }^{1}$ We recognise that methodological innovation is not confined to qualitative approaches and that there has been considerable innovation in quantitative methods as well as in mixed methods approaches that transcend the qualitative/quantitative division. Our reason for focusing on qualitative approaches only was that this reflected our own methodological expertise which we felt was necessary to enable us to pursue issues of relevance in the cases.

${ }^{2}$ Our focus was on academic citations but we are aware that the methods focused on in these cases have had considerable uptake in the business, charitable and professional sectors.

${ }^{3}$ In 2003 The Times Educational Supplement and in 2004 The Guardian newspaper reported on Kellett's approach and her research. The Radio 4 programme 'The Learning Curve' also reported it in 2003.

${ }^{4}$ David Gauntlett was featured on the front page of the Times Higher Education Supplement in 2005 with the headline 'Lego and professor click over research' 


\section{References}

Alasuutari, P. (2007) 'The globalization of qualitative research'. In C. Seale, G. Gobo, J. Gubrium and D. Silverman (Eds.), Qualitative research practice (pp. 507-520). London: Sage.

Bardsley, N. \& Wiles R. (2006) A Consultation to Identify the Research Needs in Research Methods in the UK Social Sciences. ESRC National Centre for Research Methods.

http://eprints.ncrm.ac.uk/412/

Bengry-Howell, A., Wiles, R., Nind, M. \& Crow G. (2011) A Review of the Academic Impact of Three Methodological Innovations: Netnography, Child-Led Research and Creative Research Methods. National Centre for Research Methods.

http://eprints.ncrm.ac.uk/1844/

Bryman, A. (1998) 'Quantitative and qualitative research strategies in knowing the social world'. In T. May \& M. Williams (Eds.) Knowing the Social World (pp. 138-156). Buckingham: Open University Press.

Coffey, A. (2011) 'Revisiting innovation in qualitative research', Qualitative Researcher 13: 1-2.

Dutton, W.H. and Blank, G. (2011), Next Generation Users: The Internet in Britain, Oxford Internet Survey 2011, Oxford Internet Institute: University of Oxford.

Fielding, N. and Lee, R. (1996) 'Diffusion of a Methodological Innovation: CAQDAS in the UK', Current Sociology vol. 44(3) 242-258

Frankham, J. (2009) Partnership research: a review of approaches and challenges in conducting research in partnership with service users. NCRM Methodological Review Paper 013. Downloaded 5/4/12 from http://eprints.ncrm.ac.uk/778/

Friedland, R. and Mohr, J. (Eds.) (2004) Matters of Culture: Cultural Sociology in Practice Cambridge: Cambridge University Press

Gauntlett, D. (2007). Creative Explorations: New approaches to identities and Audiences London: Routledge.

Hammersley, M. (2008) Questioning Qualitative Inquiry London

Hine, C. (2000) Virtual Ethnography. London: Sage.

Hirschman, A. (1991) The Rhetoric of Reaction: Perversity, Futility, Jeopardy. Cambridge, MA: The Belknap Press of Harvard University Press.

Hooley, T., Wellens, J. and Marriott, J. (2012) What Is Online Research? London: Bloomsbury Academic

Housley, W. and Smith, R. (2010) 'Innovation and reduction in contemporary qualitative methods: the case of conceptual coupling, activity-type pairs and auto-ethnography', Sociological Research Online 15(4) 9 http://www.socresonline.org.uk/15/4/9.html

Johnson, S. (2010) Where Good Ideas Come From: The Natural History of Innovation London: Penguin

Kellett, M. (2005) How to Develop Children as Researchers: a step by step guide to teaching the research process. London: Sage. 
Kellett, M. (2010) Rethinking Children and Research London: Continuum.

Kozinets, R. V. (2002) 'The Field Behind the Screen: Using Netnography For Marketing Research in Online Communities', Journal of Marketing Research, 39, 61-72.

Kozinets, R. V. (2010). Netnography: Doing Ethnographic Research Online. London: Sage.

Kozinets, R. (2012) 'Marketing Netnography: Prom/ot(ulgat)ing a new research method', Methodological Innovations Online 7(1): 37-45

Kuhn, T. (1962) The Structure of Scientific Revolutions. Chicago: University of Chicago Press

Lee, R. (2011) “"The most important technique ...": Carl Rogers, Hawthorne and the Rise and Fall of Nondirective Interviewing in Sociology', Journal of the History of the Behavioural Sciences 47(2): 123-146

Mason, J. (2012) 'Facet methodology: the case for an inventive research orientation', Methodological Innovations Online 6(3) 75-92.

Pink, S. (2009) Doing Sensory Ethnography. London: Sage.

Prosser, J. and Loxley, A. (2008) Introducing Visual Methods. NCRM Methodological Review Paper Discussion Paper 010. Downloaded 5/4/12 from http://eprints.ncrm.ac.uk/420/

Prosser, J. (2011) 'Visual methodology: towards a more seeing research'. In Denzin, N \& Lincoln, Y. The Sage Handbook of Qualitative Research Fourth Edition. London: Sage.

Rogers, E. (2003) Diffusion of Innovations (fifth edition). New York: Free Press.

Savage, M. (2010) Identities and Social Change in Britain Since 1940: The Politics of Method. Oxford: Oxford University Press.

Taylor, C. and Coffey, A. (2008) Innovation in qualitative research methods: possibilities and challenges, Cardiff: Cardiff University.

Taylor, C. and Coffey, A. (2009) 'Editorial -- Special issue: qualitative research and methodological innovation', Qualitative Research 9(5): 523-526.

Travers, M. (2009) 'New methods, old problems: A sceptical view of innovation in qualitative research', Qualitative Research 9(2): 161-179.

Wild, H. (2012) 'The making of water cooler logic's stakeholder ethnography: composting as a metaphor for innovation', Methodological Innovations Online 7(1): 46-60.

Wiles, R., (2006) 'Researching researchers: lessons for research ethics', Qualitative Research 6(3): 283-299.

Wiles, R., Bardsley, N. \& Powell, J. (2009) Consultation on research needs in research methods in the UK social sciences. National Centre for Research Methods.

http://eprints.ncrm.ac.uk/810/

Wiles, R., Crow, G. \& Pain, H. (2011) 'Innovation in qualitative research methods: a narrative review', Qualitative Methods 11(5): 587-604.

Wiles, R., Coffey, A., Robison, J. \& Prosser, J. (2012) 'Ethical Regulation and Visual Methods: Making Visual Research Impossible or Developing Good Practice?', Sociological Research Online 17(1): 8 


\section{http://www.socresonline.org.uk/17/1/8.html}

Xenitidou, M. and Gilbert, N. (2009) Innovations in social science research methods, Guildford: University of Surrey.

Xenitidou, M. and Gilbert, N. (2012) 'Introduction to the special issue: The processes of methodological innovation narrative accounts and reflections', Methodological Innovations Online 7(1): 1-6.

\section{Biographies}

Rose Wiles is a co-director and principal research fellow at the National Centre for Research Methods at the University of Southampton. She is a sociologist with interests in qualitative methods, research ethics and health and illness. She is currently writing a book on research ethics building on her previous research in this area and conducting a research project on trust in GP: patient relationships.

Andrew Bengry-Howell is research fellow in the Centre for Sexual Health Research at the University of Southampton where he is working on a project on early sexual socialisation and sexuality education. His research interests are in qualitative methods, methodological innovation and in youth and identity, specifically the role that culture and everyday cultural practices play in young people's social identification processes.

Graham Crow is Director of the Scottish Graduate School of Social Science and Professor of Sociology and Methodology at the University of Edinburgh. He is also Deputy Director of the National Centre for Research Methods. His interests are in sociological theory, comparative sociology, and the sociology of family and community. He is currently involved with various research projects in the cross-Research Council 'Connected Communities' research programme.

Melanie Nind is a professor of education and co-director of the National Centre for Research Methods at the University of Southampton. She is co-editor of the International Journal of Research and Methods in Education and is currently researching quality and capacity in inclusive research with people with learning disabilities. 